\title{
The politics of health take centre stage in Geneva
} Ala Alwan ${ }^{1}$

This month sees the holding of the sixty-seventh World Health Assembly, which meets each year in Geneva. Attended by delegations from all 194 Member States, the Health Assembly is the highest governing body of the World Health Organization (WHO) and determines the policies of the Organization.

Just some of the key public health issues on the agenda that will be of particular interest to the countries of the Eastern Mediterranean Region as they seek to advance the health of their people are hepatitis, noncommunicable diseases, maternal, infant and young child nutrition, disability, violence, counterfeit medical products, access to essential medicines, palliative care, polio, antimicrobial drug resistance, and climate change and health. In recent years the Health Assembly has followed up closely on implementation of the WHO reform programme and this year will be no exception. Thus it will also consider how to improve its decision-making, a framework of engagement with non-State actors, follow-up on the financing dialogue initiated with Member States in 2013, strategic resource allocation and financing of WHO administrative and management costs.

The Health Assembly is an important annual event in global health governance but it is not the only venue that shapes decision-making about health. Health itself is not an isolated discipline, but subject to a wide range of determinants. So the decisions that shape how health issues are addressed at global, regional and national levels are subject also to decisions made in non-health arenas. Indeed, the 2013 Helsinki statement on Health in All Policies called on governments to include health in all policies across all sectors of government and between governments.

Health and health governance are also shaped by domestic and foreign policy concerns that are political and socioeconomic in nature. Many of the health challenges now facing both individual countries and the world in general, including all those highlighted above, have critical political and socioeconomic dimensions that require political solutions, at both the domestic and international levels. The declaration of polio on 5 May 2014 as a Public Health Emergency of International Concern has implications for all countries in the Region, and beyond. The current challenge to the eradication of polio, with the ban on immunization imposed by some groups and continuing attacks against health workers, is just one example where a political solution is needed. Technically, eradication has been proved feasible, but currently the global polio eradication programme, together with the 25 years of financial and human investment that have been made in it, is in critical need of innovative approaches and political support.

Clearly, there is increasing need for proactive health diplomacy. Health diplomacy refers to the negotiation processes that shape and manage the policy environment for health, both within countries and in the world at large. These processes take place in a variety of forums, national and international, and involve both State and non-State actors. The health sector is often not directly represented in discussions that in practice affect the health policy environment and, ultimately, population health Therefore, interaction and coordination between health, foreign policy and other sectors at the domestic level is crucial.

Earlier this month, WHO hosted the third regional seminar on health diplomacy in order to build capacity in this important area, focusing on some of the current health challenges of priority and relevance to the Region, such as health security, noncommunicable diseases and antimicrobial resistance, and to raise awareness of the value of integrating concepts of health diplomacy into foreign policy. Participants included senior officials from ministries of foreign affairs and health, ambassadors, deans of diplomatic academies, regional public health institutes, heads of parliamentary committees and other stakeholders.

Health diplomacy is particularly important for the Region because many of the development issues its Member States face relate directly to health, and because it is disproportionately affected, compared with other regions, by manmade and humanitarian crises. Political solutions are therefore of direct relevance, 
while engagement of representatives of Member States in decision-making processes on global health issues is equally important in protecting their interests.

We have already started to see positive outcomes of the seminar, with several countries now committed to including health diplomacy in their training for diplomats. As the World Health Assembly proceeds, and as the United Nations continues with the consultation process for the post-2015 agenda, I hope that the Member States of the Region will put more emphasis on the importance of health diplomacy in their negotiation preparations, in these and all areas that impact on health. 